\title{
Fazer laudos: algumas questóes teórico-metodológicas de uma práxis institucionalizada
}

\author{
FLÁVIO LUIS ASSIZ DOS SANTOS
}

\section{Introdução}

Fazer laudos. Esta expressão, muito utilizada entre antropólogos/as que se dedicam ao trabalho pericial no Brasil, refere-se a um "termo nativo" deste campo de atuação profissional que circunscreve uma série de questões de diversas naturezas inerentes a esta práxis. Trata-se de um saber-fazer especializado que afeta sobremaneira a carreira e a vida dos/das antropólogos/as, tanto por exigir-lhes competências específicas, quanto por se constituir em experiências sui generis. Neste artigo $^{1}$ apresento algumas questões teórico-metodológicas que povoam o universo dessa prática profissional especializada, a partir do exame detalhado de laudos ditos "antropológicos", associado a entrevistas com os/as seus/ suas autores/as, produzidos no bojo de processos administrativos de reconhecimento territorial quilombola que tramitam na Superintendência Regional do Instituto Nacional de Colonização e Reforma Agrária (INCRA) ${ }^{2}$ na Bahia, de 2003 a $2018 .^{3}$

1 Uma versão preliminar deste texto foi apresentada na Mesa Redonda 04 - Atuação Antropológica Junto aos Processos Jurídicos e Administrativos envolvendo Territórios Quilombolas, na VI Reunião Equatorial de Antropologia, ocorrida em Salvador/BA, entre 09 a 12 de dezembro de 2019, que contou com participação dos antropólogos/as Mariana Balen Fernandes (UFRB), Ugo Maia Andrade (UFS) e da historiadora Neivalda Freitas Oliveira (UNEB).

2 O Instituto Nacional de Colonização e Reforma Agrária (INCRA) é uma autarquia federal, cuja missão prioritária é executar a reforma agrária e realizar o ordenamento fundiário nacional. Criado pelo Decreto $\mathrm{n}^{\circ} 1.110$, de 9 de julho de 1970, atualmente o Incra está subordinado ao Ministério da Agricultura, Pecuária e Abastecimento (MAPA) e implantado em todo o território nacional por meio de 30 superintendências regionais (SR's). Dentre as ações desenvolvidas pelo INCRA temos: a desapropriação de imóveis rurais, a implantação do programa nacional de reforma agrária, a concessão de crédito instalação aos assentados, construção de infraestrutura nos assentamentos de reforma agrária, fomento a ações produtivas nos projetos de assentamento, gestão do programa de assistência técnica, social e ambiental aos projetos de assentamento, a titulação das áreas de reforma agrária, a gestão do programa de educação da reforma agrária, a gestão do cadastro rural, o georeferenciamento e a certificação dos imóveis rurais, controle da aquisição de terras por estrangeiros, a regularização fundiária na Amazônia Legal, a regularização fundiária dos territórios quilombolas, dentre outros (www.incra.gov. br, acesso em 11/04/2019).

3 Este artigo apresenta alguns resultados de minha tese de doutorado intitulada Antropologia e Estado: Uma Etnografia dos Processos de Reconhecimento Territorial Quilombola na Babia (2003-2018) (Santos, 2019), orientada pela Profa. Dra. Ana Paula Comin de Carvalho. 
A produção de laudos (ou relatórios) ${ }^{4}$ antropológicos para reconhecimento dos territórios quilombolas no Brasil é uma prática administrativa e antropológica que teve início na década de 1990, inicialmente financiados e regulamentados pela Fundação Cultural Palmares (FCP). ${ }^{5}$ A partir de então, os/as antropólogos/as brasileiros, em meio a um campo de disputas com outras áreas do conhecimento, sobretudo a História, foram acionados como experts para responder às demandas técnico-científicas postas ao Estado para a operacionalização do art. 68 do Ato das Disposições Constitucionais Transitórias, da Constituição Federal de 1988, que garante aos remanescentes das comunidades dos quilombos o direito à propriedade definitiva das suas terras e atribui ao Estado o dever de emitir os respectivos títulos. Desde 2003, com a publicação do Decreto 4.887, a elaboração de laudos (ou relatórios) antropológicos quilombolas passaram ser produzidos e disciplinados pelo INCRA, através de Instruções Normativas ("INs"). ${ }^{6}$

Ao longo desses 15 (quinze) anos, os laudos antropológicos foram incorporados à prática administrativa da autarquia agrária para subsidiar ações fundiárias de reconhecimento e titulação dos territórios quilombolas, municiando o órgão com informações antropológicas, etnográficas, históricas, culturais, socioeconômicas, geográficas, ambientais e documentais sobre esses grupos étnicos. Estes laudos são resultantes de um trabalho pericial (ou "trabalho de campo", como muitos/as antropólogos/ as preferem chamar ${ }^{7}$ ) e têm um caráter técnico-científico, que advém do uso de um saber especializado calcado no conhecimento acadêmico, na adesão às normas técnicas, jurídicas e administrativas e da sua elaboração por servidores públicos ou contratados (e fiscalizados) pelo Poder Público, dando, em termos jurídicos, a garantia da "neutralidade". Segundo Laraia (1994: 11), os desafios advindos dessa atividade complexa, de alta responsabilidade, que envolve a tradução dos conhecimentos antropológicos para a linguagem jurídica, demandou grande esforço e abertura dos/as antropólogos/as para dialogar com os operadores do Direito, aprender a lidar com os procedimentos e conceitos jurídicos e desenvolver competências específicas necessárias à sua produção. Tais competências não são adquiridas nos cursos de graduação e pós-graduação que formam antropólogos/as no Brasil, mas foram (estão) sendo forjadas na prática.

Segundo dados do INCRA, de 2003 a 2018, foram produzidos e publicados em todo Brasil 278 (duzentos e setenta e oito) laudos antropológicos de identificação e delimitação de territórios quilombolas, elaborados sob diferentes modalidades de execução: convênios, contratos, execução direta, termos de cooperação técnica, doações etc. A Superintendência Regional do INCRA na Bahia foi a que mais produziu relatórios neste período, totalizando 37 (trinta e sete) relatórios publicados, consti-

4 Neste campo de atuação profissional, tanto o termo "laudo antropológico" como o termo "relatório antropológico" são utilizados.

5 A FCP é um órgão vinculado atualmente à Secretaria da Cultura que tem como missão promover e preservar os valores culturais, históricos, sociais e econômicos decorrentes da influência negra na formação da sociedade brasileira.

6 De 2003 até hoje, o INCRA publicou 05 (cinco) Instruções Normativas regulamentando o Decreto 4.887/2003, promovendo várias alterações procedimentais. Foram as IN 16/2004, 20/2005, 49/2008, 56/2009 e 57/2009.

7 O termo "perícia” é um jargão do campo jurídico que foi incorporado neste campo profissional e os/as antropólogos/as têm diferentes concepções sobre ele. Uns parecem ver perícia com uma espécie de "estar lá" que serve para justificar antropologicamente o território a ser regularizado. Outros parecem encarar o termo perícia como um sinônimo de "comprovação", que se aproximaria da ideia dos laudos forenses ou da polícia técnica. Existem aqueles que se recusam a pensar este trabalho como pericial. Alguns só se referem à perícia em termos de pesquisas antropológicas feitas no âmbito do Poder Judiciário, para responder aos quesitos postos pelo juízo ou em juízo, enquanto outros usam o termo indistintamente tanto em contextos de processos administrativos como de processos judiciais. 
tuindo-se, assim, num importante locus de análise devido à quantidade e diversidade de experiências. ${ }^{8}$ Sou servidor de carreira do INCRA e fui, entre 2004 e 2016, o gestor do Serviço de Regularização de Territórios Quilombolas do INCRA no Rio Grande do Norte e na Bahia, coordenando diversas equipes técnicas que elaboraram laudos antropológicos nos dois estados. Portanto, foi a minha posição neste campo e a experiência profissional acumulada que motivaram para a realização de uma pesquisa que tomou a própria produção dos laudos antropológicos como objeto de estudo (e não de um laudo antropológico específico). Tive como referência os 37 (trinta e sete) laudos publicados na Bahia, de 2003 a 2018, que estavam à minha disposição como fonte de pesquisa e fiz 32 (trinta e duas) entrevistas com os/as antropólogos/as laudistas. O objetivo geral da pesquisa foi levantar as questões antropológicas que estão sendo concebidas e veiculadas neste contexto de uma práxis especializada. Tanto a análise dos laudos como as entrevistas com os/as antropólogos/as tiveram o propósito de fomentar uma reflexividade antropológica das experiências do fazer laudos.

\section{Algumas questões teórico-metodológicas na/da produção dos relatórios antropológicos quilombolas}

O’Dwyer $(2005,2010)$ sinaliza para um aumento da participação dos profissionais de antropologia no aparelho de Estado (como funcionários públicos concursados), o que tem deixado a fronteira entre atividades de pesquisa realizadas dentro e fora da academia com limites menos rígidos. As pesquisas para produção das "peças técnicas" denominadas laudos/relatórios antropológicos diferem muito do campo das pesquisas antropológicas convencionais (para a produção de teses e dissertações), embora não se trate de uma antropologia de segunda qualidade ou menos rigorosa. A questão dos laudos entrou definitivamente na agenda antropológica brasileira e, na última década, este tema foi adensado com o aumento da demanda por laudos/relatórios antropológicos de identificação e delimitação dos territórios quilombolas, cujos marcos normativos e metodológicos foram influenciados pelo acúmulo de experiências prévias dos relatórios de demarcação das terras indígenas. Contudo, evidentemente, os relatórios quilombolas trouxeram novos elementos para esse debate. Podemos dizer que está se constituindo no Brasil uma espécie de subcampo dentro do campo da antropologia brasileira que trata desta questão e situa-se numa zona de fronteira entre a antropologia acadêmica e uma antropologia da ação, apresentando especificidades.

Tomando como referência a identificação das terras indígenas no Brasil, Lima \& Barreto Filho (2005) tratam da questão da relação entre antropologia e saberes administrativos buscando a compreensão sociológica e histórica desta prática.

As relações entre antropologia e saberes administrativos no Brasil têm sido tematizadas nos últimos anos, ainda que em pronunciamentos breves, denúncias angustiadas, ou textos curtos com o intento de provocar discussões mais substanciais. Versões variadas da participação de antro-

\footnotetext{
8 As superintendências regionais do INCRA que mais publicaram relatórios técnicos neste período foram: 1. Bahia, com 37 relatórios; 2. Maranhão, com 25 relatórios e 3. Rio Grande do Sul, com 23 relatórios. Dados consultados no site: http://www.incra.gov.br/ sites/default/files/incra-andamentoprocessos-quilombolas_quadrogeral.pdf, acesso em 09/05/2019
} 
pólogos em esferas de aplicação de políticas governamentais têm sido veiculadas: desde as mais heróicas e exultantemente triunfalistas, pregando um suposto (sempre presente) engajamento cidadão, passando pelas deprimidas e preocupadas, que marcam o despreparo dos profissionais da antropologia em ação nesses campos no país, o que os tornaria presas fáceis do poder das rotinas organizacionais; até as de matizes "técnicos", com pretensões à neutralidade política e às ambiçôes ao crescimento do mercado de trabalho, visando à "profissionalização" (bastante interessada) da disciplina no país. (Lima \& Barreto Filho 2005: 09)

As ações de identificação e delimitação dos territórios quilombolas também podem ser tomadas, nos termos destes autores (idem), como uma "megaoperação" de codificação governamental das demandas territoriais e culturais de grupos étnicos que interpõe "efeito de Estado de enorme importância" e permite pensar "as mudanças e permanências na própria disciplina antropologia e na formação do antropólogo". Para tanto, considerando as mudanças ocorridas nas diversas etapas do procedimento de regularização fundiária e a participação progressiva dos antropólogos (como um técnico reconhecido e de quem se espera um papel multifuncional) na definição das terras indígenas, os autores buscaram fomentar a construção de uma "sociologia das identificações". Com essa obra os autores tiveram a intenção de registrar um determinado momento do fazer antropológico no Brasil (dos anos 1990), estimulando outras pesquisas e publicações similares, vez que consideram "este gênero da atuação" dos antropólogos (os relatórios) pouco tratados intelectualmente.

Segundo L'Estoile et al (2002: 18), o trabalho dos antropólogos no Brasil tem uma estreita relação com a formulação de políticas estatais. Para eles, há, entre a Antropologia e o Estado, uma dupla dimensão de instrumentação e de legitimação, entretanto a identidade profissional dos antropólogos hoje tende a valorizar um ideal de autonomia com relação ao Estado e seus órgãos, o que leva à minimização da existência de relações com o mundo da política, ou a tratá-las apenas como desvios a serem eliminados no processo de produção da teoria. Portanto, as considerações a respeito da participação dos antropólogos na elaboração e implementação das políticas públicas, sobretudo as voltadas para os grupos sociais tidos como primitivos, atrasados, marginais, tribais, subdesenvolvidos ou pré-modernos, são habitualmente objeto de julgamentos morais e políticos, vistos através das lentes da denúncia e do engajamento, e não do ponto de vista da análise sociológica. O que os autores defendem é a superação disto, propondo o exame de casos concretos de um ponto de vista histórico e comparativo, à luz da história social das ciências sociais, da sociologia do conhecimento científico e da etnografia do Estado, a partir de uma perspectiva compreensiva das relações entre saberes antropológicos e a construção dos Estados nacionais.

A compreensão sociológica da dinâmica da relação dos antropólogos e os estados só é possível se levarmos em conta o caráter estrutural (e estruturante) dessa relação, que nada tem a ver com patologias, ou com formas desviadas (ou menores) de conceber e de praticar a antropologia (L'Estoile et al 2002: 13).

Para Lima (2015: 30), o aumento da atuação dos antropólogos em espaços extra universitários ainda carece de maiores investimentos analíticos no âmbito dos cursos de formação universitária. Segundo ele, muitos estudos antropológicos sobre temas relativos às sociedades contemporâneas (entre 
eles o Estado e suas políticas públicas) são motivados e viabilizados em virtude da inserção profissional dos pesquisadores. Como diz: "inserção profissional e reflexão analítica criativa podem se beneficiar mutuamente" (idem). As informações geradas pelos antropólogos e outros agentes em contexto de formulação, implementação e avaliação de políticas públicas podem ser uma fonte permanente de reflexão.

No entanto, os laudos antropológicos são produzidos num contexto de atuação estatal em que os agentes dificilmente fazem reflexões e autorreflexões sobre "o que se faz", "como se faz" e as "consequências do que se faz". Os/as antropólogos/as têm toda a experiência do "saber fazer" que "se aprende fazendo", mas quase sempre não sobra tempo para exercitar a reflexividade sobre essas ricas experiências etnográficas. Seria o "tempo extra", nos termos de um antropólogo com quem conversei. Assim, as análises críticas sobre essa "Antropologia da ação" (O’Dwyer 2010) acabam ficando a cargo de pesquisadores externos e no âmbito apenas acadêmico. Esta pesquisa ensejou, portanto, preencher um pouco essa lacuna ao dar voz aos laudos e seus autores.

O trabalho de identificação e a delimitação de um território quilombola - etapa inicial dos procedimentos administrativos para a seu reconhecimento - exige da equipe responsável pela elaboração dos relatórios técnicos estratégias diferenciadas de atuação, o enfrentamento de muitos desafios e implica numa enorme responsabilidade social e política. ${ }^{9}$ A elaboração de cada relatório antropológico (e outros relatórios técnicos inerentes a esta atividade) apresenta suas próprias vicissitudes, oriundas da realidade socioespacial pesquisada, do contexto político e normativo, das relações estabelecidas entre os agentes sociais em contato e da formação acadêmica e política dos técnicos. Não é possível, portanto, estabelecer uma "manualização" para essa prática, um parâmetro técnico único para responder à pergunta: "como se faz um laudo antropológico?". Muito embora exista uma Instrução Normativa sobre o tema, esta não é um instrumento capaz e suficiente para disciplinar todas as possíveis situações que envolve a prática antropológica de produção de laudos antropológicos.

Os laudos antropológicos trazem grandes repercussões na vida social dos grupos quilombolas estudados, uma vez que subsidiam inúmeras intervenções públicas (e privadas) e contribuem para reposicionar estas comunidades no âmbito das correlações de poder instituídas e perante o próprio Estado. Eles são elaborados em meio a muitas expectativas, tanto dos quilombolas que "sempre acham que ele é mais do que realmente é”, quanto dos agentes públicos (gestores, operadores do Direito etc.) e dos demais interessados (fazendeiros, mediadores etc.). Esta situação provoca nos profissionais envolvidos com essa prática muitas tensões e um enorme senso de responsabilidade. Os quilombolas muitas vezes consideram que o relatório antropológico é o texto que "vai salvar a vida deles", pois resolverá os conflitos fundiários e outros problemas vivenciados. No entanto, o relatório antropológico faz parte de uma primeira etapa do processo de titulação que, via de regra, tem se alongado por muitos anos por causa da excessiva burocratização, das dificuldades financeiras e estruturais e, sobretudo, pela falta de "vontade política".

Malgrado o esforço da Superintendência Regional do INCRA/BA para viabilizar a produção dos laudos/relatórios antropológicos, sobretudo nos primeiros anos após 2003, nenhum território qui-

9 Para aprofundamento desta questão, ver Ferreira (2012). 
lombola foi titulado. O aprendizado com as diversas experiências de produção dos relatórios técnicos ao longo desses 15 (quinze) anos instrumentalizou o INCRA para lidar com as questões quilombolas, desenvolvendo na autarquia agrária uma expertise, fruto de enormes investimentos financeiros e da capacitação (em cursos de curta duração, de pós-graduação e em seminários, mas, sobretudo, em serviço) de recursos humanos altamente qualificados e especializados. Ademais, os relatórios técnicos, além de legitimar as ações do Estado nesta matéria, são também importantes fontes de pesquisa histórica, geográfica, sociológica, ambiental e etnográfica sobre os grupos quilombolas brasileiros. Contudo, nos últimos anos, em virtude da falta de priorização política, das reações dos ruralistas e da conjuntura fiscal e política do país, os processos administrativos de titulação dos territórios quilombolas têm enfrentado enormes entraves nas esferas dos três poderes da República. Como consequência, as comunidades quilombolas que foram objeto dos relatórios técnicos aguardam a efetivação dos seus direitos territoriais, consagrados constitucionalmente.

Todos/as os/as antropólogos/as com quem conversei problematizaram os seus laudos antropológicos em oposição às pesquisas acadêmicas (para monografias, teses, dissertações, artigos etc.), destacando, contudo, o caráter técnico-científico do seu trabalho. Concordam que a pesquisa para um relatório técnico é mais dirigida, não pautada pelos interesses do/a pesquisador/a, mas pelos interesses das comunidades e do Estado. O objetivo da pesquisa/perícia está previamente delineado e não há margem para alterações: já se vai a campo sabendo o que precisa ser feito, sendo necessário, contudo, decidir "como fazer". Não é um texto pautado pelos interesses genuínos da pesquisa acadêmica, cujos objetivos, em geral, restringem-se ao projeto do/da pesquisador/a. Ao contrário, é um texto "encomendado", cujos objetivos são previamente estabelecidos pela agência que o contratou, e voltado para atender uma demanda posta pela realidade social. É um texto elaborado, via de regra, com a colaboração atenta dos interessados e escrito para determinados leitores, que não os pares acadêmicos e com determinado objetivo de reconhecimento de direitos territoriais. Por seu caráter "técnico", espera-se dele uma linguagem objetiva e didática, o cumprimento das exigências legais-normativas e uma justificativa convincente para o Estado designar e/ou reconhecer parte do território nacional para um grupo social.

A "megaoperação" de transformar uma experiência de campo eivada de conflitos, pressões, tensões e expectativas múltiplas em um "texto" é algo que suscita estratégias muito específicas e exige cuidados redobrados dos/das redatores (as). Conforme apontou Silva (2015), o trabalho etnográfico de produção de cada relatório apresenta "um quadro complexo de interações entre diversos agentes" e o texto etnográfico "sedimenta" e "equacionaliza" as múltiplas vozes dos atores envolvidos, inclusive dos seus próprios autores. Escrever um relatório dessa natureza é algo que demanda dos/as antropólogos/ as inúmeras competências e, ao mesmo tempo, desenvolve um tipo específico de gênero textual.

Uma competência fundamental para a produção de um laudo antropológico é saber manejar adequadamente um arsenal teórico-conceitual, sobretudo do campo das Ciências Humanas e Sociais (mas também de outros campos do conhecimento). Nesta prática profissional, o desafio que está sempre colocado é o da construção de narrativas plausíveis sobre a história e a territorialidade das comunidades, forjadas num diálogo com o Direito, com os quilombolas e com os mediadores. O que está em jogo é o melhor enquadramento técnico-científico para as comunidades quilombolas (esses novos 
"sujeito de direitos") e a melhor forma de explicar a "quilombolidade"10 de determinados grupos sociais, construindo uma justificativa, ancorada etnograficamente, para o reconhecimento dos territórios quilombolas.

Fazer laudos enseja diversas preocupações técnicas e ético-políticas que passam pela necessidade de fundamentar com coerência a reivindicação territorial das comunidades quilombolas e não as prejudicar em função de inconsistências e vícios no processo administrativo. A própria escrita do texto tem suas peculiaridades pelo seu caráter "mais palatável”, uma vez que há a necessidade de o texto etnográfico, neste caso, ser compreendido, por exemplo, por um gestor, um advogado e convencer um juiz, dando resposta a outras expectativas que não só as das comunidades. É uma escrita "mais controlada", sempre medindo como abordar os dados para não expor as comunidades a nenhuma situação de perda de direitos. O que não significa abrir mão da linguagem antropológica, mas escrever um texto menos acadêmico.

Silva (2015: 151) afirma que os interesses dos/das antropólogos/as no que ela chamou de "pós -ocasião etnográfica" se colocam de modo mais marcante para os/as antropólogos/as-peritos/as do que no caso dos/as antropólogos/as estritamente acadêmicos. Desta forma, estes interesses estão na própria "base do laudo". No processo de produção de um laudo antropológico, os seus autores, quase sempre, levam em consideração algumas questóes que poderão aparecer no "pós-texto", tais como as possíveis contestações (administrativas e/ou judiciais), seja por parte dos proprietários privados (comumente chamados de "fazendeiros") ou por parte de outros órgãos públicos (como os órgãos ambientais, por exemplo). Assim, muitas vezes, o “texto” já antecipa o "pós-texto”, ou seja, fazer laudo é um exercício etnográfico de conjecturar prováveis reações aos textos e contemporizá-las.

10 Tomei o termo a partir da leitura de Steuernagel (2010). Embora o autor não defina explicitamente o que ele considera como "quilombolidade", aqui utilizo o termo como a qualidade (ou as qualidades) que caracterizam uma comunidade como "quilombola". 


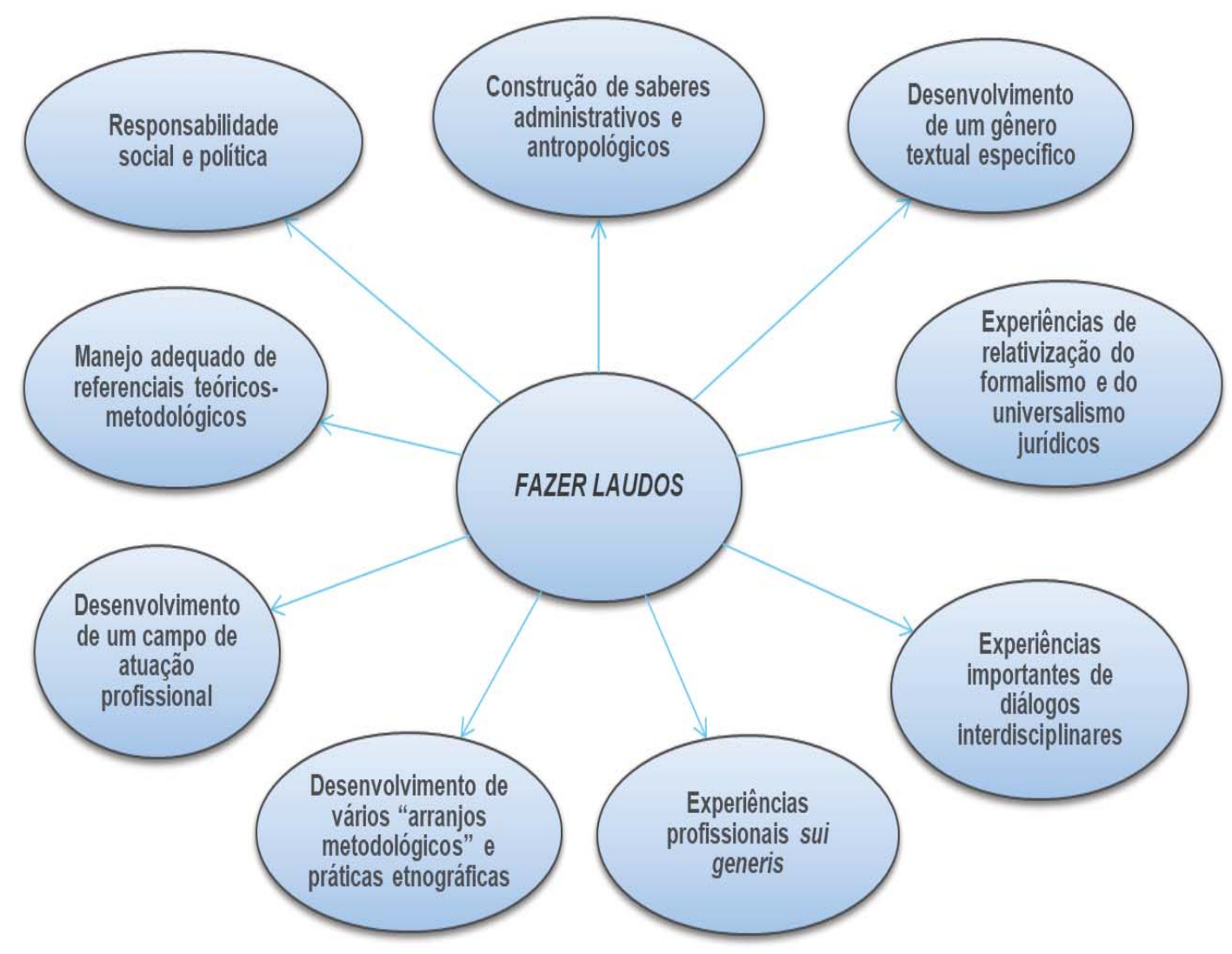

Figura 1 - Fazer laudos: questões teórico-metodológicas de uma práxis especializada Elaboração: Flavio Luis Assiz dos Santos, 2019.

Produzir um laudo antropológico envolve um esforço intelectual, institucional e pessoal para adequar a legislação à realidade e vice-versa. Os/as antropólogos/as, manejando com vários tipos de narrativas, fazem uma importante operação de tradução da realidade social para a linguagem jurídica. A Antropologia, neste contexto de diálogo com o cotidiano e permanente com os operadores do Direito, tem um potencial de "arejamento" (de ampliação dos horizontes) uma vez que os textos etnográficos são construídos "com as pessoas", a partir de uma escuta atenta e interessada de muitas vozes. Os laudos (os textos) resultam de um processo de análise dos/as antropólogos/as (e demais técnicos), que buscam entender as relações sociais e de poder que estão em jogo e trabalha com as diversas narrativas como insumos.

Os textos jurídicos, em geral, são mais exegéticos, comunicando-se mais com o próprio campo jurídico. Contudo, a descrição e análise da de produção de relatórios antropológicos de identificação e delimitação territorial quilombola evidencia como a relação entre Antropologia e Direito, marcada por controvérsias e tensões, apresenta também elementos de aproximação interdisciplinar, estimulada pelo objetivo comum, dentro dos "autos dos processos administrativos", de elaboração conjunta da "melhor interpretação da lei" em favor das comunidades quilombolas. Os/as antropólogos/as, ao fazer laudos sem abdicar dos pressupostos teórico-metodológicos da Antropologia, mas se apropriando dos 
códigos jurídicos e problematizando-os, contribuem para a relativização do formalismo e do universalismo jurídicos. Desta forma, neste campo de atuação profissional, são como uma espécie de "operadores do direito auxiliar", sem, claro, poder de controle sobre o campo jurídico (e nem do administrativo).

Uma característica da "tecnicidade" dos laudos antropológicos é sua orientação jurídico-formal dada pelas Instruções Normativas, que são instrumentos administrativos/legais de comunicação entre o campo técnico-científico, o campo jurídico e a sociedade em geral. É muito recorrente as críticas, sobretudo em eventos acadêmicos, sobre um certo "engessamento" da prática antropológica provocada pela burocratização normativa. Os/as meus/minhas interlocutores/as apresentaram posicionamentos diversos quanto a isto, cada um/uma elaborando distintamente a sua relação com as Instruções Normativas. Para alguns/algumas, as Instruções Normativas servem para "uniformizar para quem vai ler" (numa perspectiva externa, dos/as leitores/as) e "ajuda a chamar a atenção para os dados que a gente precisa ter realmente" (numa perspectiva interna, do/a autor/a). Outros/outras consideraram que as Instruções Normativas são "até bem amplas", não representando uma "camisa de força” pois existe uma liberdade de escrita e tópicos não previstos na norma podem ser acrescentados, caso necessário. Há aqueles/aquelas que veem problemas em alguns pontos exigidos nas normativas por considerá-los “excessivos” e, se não pesquisados e anunciados nos relatórios, podem dar margem para contestações (por descumprimento da normativa). Contudo, todos/as reconheceram que neste campo de atuação profissional um mínimo de direcionamento é necessário, daí a imprescindibilidade de uma normativa.

Percebi nesta etnografia que, em geral, as Instruções Normativas não são utilizadas como uma espécie de questionário ou de sumário (um guia para o texto), mas como documento balizador para os trabalhos de campo. É claro que os/as antropólogos/as têm o cuidado de abordar todos os itens exigidos nas Instruções Normativas, no entanto, os tipos de organização da estrutura textual dos relatórios são os mais diversos. Isto sinaliza para uma certa margem de criatividade possível neste campo de atuação profissional, relacionada ao "mínimo de discricionariedade" dos agentes públicos.

Uma questão fundamental para a produção de laudos antropológicos quilombolas é a capacidade, esperada dos/as antropólogos/as, para promover um mapeamento do papel de todas as instituiçóes públicas envolvidas com a regularização fundiária em curso, entendendo o seu funcionamento e estabelecendo relações (às vezes até pessoais) com os seus agentes. Cada situação empírica objeto de uma identificação e delimitação quilombola pode exigir da equipe técnica conhecimentos especializados relativos à competência de um determinado órgão público, como a Secretaria do Patrimônio da União (SPU), o Instituto Chico Mendes de Conservação da Biodiversidade (ICMBio), do Instituto Brasileiro de Meio Ambiente (IBAMA) e as Forças Armadas, quando os territórios quilombolas incidem sobre áreas da União, de Unidades de Conservação e de Segurança Nacional, entre outras situações fundiárias de sobreposição. As equipes técnicas normalmente não ficam alheias a isto, mesmo porque, após a publicação, vários órgãos públicos se manifestam sobre os laudos produzidos, podendo interferir no curso do processo administrativo. O Estado é uma máquina de produção de procedimentos e regulamentações e, em cada situação concreta de identificação e delimitação territorial quilombola, a equipe técnica precisa manejar estes procedimentos e regulamentações com conhecimento e competência. 
Assim, fazer interlocuções e mediações com outras instituições públicas, ajudando a construir soluções para a estabilização do território delimitado, é outra habilidade que, quase sempre, os/as antropólogos/as exercitam na produção de um laudo de natureza técnico-científica. Não estou me referindo, de forma alguma, as mediações espúrias, que prejudiquem as comunidades quilombolas, sem atentar para os compromissos éticos inerentes à profissão. Sabemos que decisão final sobre o território a ser titulado não cabe aos antropólogos/as, mas às instâncias decisórias do Estado brasileiro, entretanto, uma peça técnico-científica bem fundamentada constitui-se num instrumento importante de defesa (inclusive perante o Poder Judiciário) e de reconhecimento dos direitos territoriais (e outros) das comunidades.

Por fim, uma questão fundamental desse campo de atuação profissional diz respeito a interdisciplinaridade. Não se faz um laudo antropológico sozinho/a e com os instrumentos (teóricos e técnicos) de apenas uma área do conhecimento. As exigências normativas e os próprios desafios colocados pela complexidade do trabalho demandam dos antropólogos/as um "alargamento do olhar”. A participação de geógrafos/as, agrônomos/as, biólogos/as, agrimensores, historiadores/as e outros cientistas humanos, sociais e ambientais é uma realidade neste campo e este relacionamento interdisciplinar compulsório tem trazido muitas incompreensões e disputas, mas também profícuos diálogos. Ouvi muitos relatos de antropólogos/as que creditaram determinados aprendizados e parte de suas análises como fruto do contato e do diálogo com outros profissionais.

Diversos arranjos, fruto de distintas formas de relacionamento interdisciplinar, são forjados nas experiências de produção de laudos. Não obstante seja uma exigência normativa e inerente à própria natureza dos trabalhos de identificação e delimitação dos territórios quilombolas, uma maior ou menor abertura dos/as antropólogos/as para a interdisciplinaridade depende da trajetória específica dos sujeitos ou das suas experiências prévias com trabalho em equipe. Em geral, as soluções metodológicas encontradas levam em consideração a necessidade de produção de uma pesquisa com celeridade e que procure articular os diferentes campos de conhecimento mobilizados para uma "confluência analítica" que justifique a reivindicação territorial das comunidades. Procura-se sempre evitar que o produto final (o laudo) seja um amontoado de documentos sem uma "liga" entre si. O caráter interdisciplinar de um laudo antropológico não significa que todos os profissionais devem trabalhar juntos e, ao final, o produto deve ser uma "salada". Num contexto que exige vários olhares acadêmicos, cada profissional deve ter muita competência e segurança na sua área específica para que, no diálogo com os outros saberes, este consiga alimentar ainda mais o seu olhar especializado e não se perca em meio a uma proliferação de possibilidades analíticas. Assim, a capacidade de ouvir e de estar aberto ao diálogo generoso deve ser exercitada sem perder o foco nas contribuições técnicas que cada um pode oferecer.

\section{Considerações Finais}

A produção de laudos antropológicos, como instrumentos inerentes à política pública de reconhecimento e titulação de territórios específicos, é substancialmente uma prática estatal, vez que são financiados, regulamentados, valorados e utilizados principalmente pelo Poder Público. Tratam-se 
de saberes administrativos e antropológicos forjados a partir de práticas cotidianas de trabalho que, muitas vezes, são apagadas no curso do tempo, mas, conforme aponta Castilho et al (2014: 22), são ângulos privilegiados para a análise antropológica. Contudo, este campo de atuação profissional tem sido pouco pesquisado a partir da perspectiva das ações concretas dos agentes que operacionalizam essa política pública e de seus "produtos".

O exercício da produção de laudos antropológicos se constitui numa complexa atribuição para os/as antropólogos/as que necessitam mobilizar diversas competências (teóricas, metodológicas e práticas) que estão circunscritas, usualmente, à tradição disciplinar da Antropologia. Nesta pesquisa escutei diversas vezes que "os bons laudos são aqueles que fazem boas etnografias". Assim, fazer laudos não é uma atividade menor dentro do campo de atuação antropológica e nem deve ser vista como uma mera aplicação de conhecimentos técnicos e acadêmicos. Do contrário, a produção de laudos antropológicos envolve assuntos de relevância teórica e metodológica. Obviamente que esse tipo específico de trabalho enseja uma prática profissional em consonância com as vicissitudes e os desafios inerentes a esta demanda específica, não se confundindo com o modelo clássico das etnografias, ao estilo malinowiskiano.

\author{
Flávio Luiz Assis do Santos é doutor em Antropologia pela Universidade \\ Federal da Bahia (UFBA) e servidor do Instituto Nacional de Colonização e \\ Reforma Agrária (INCRA).
}

\title{
REFERÊNCIAS BIBLIOGRÁFICAS
}

BARRETTO FILHO, Henyo Trindade; LIMA, Antonio Carlos de Souza (org.). 2005. Antropologia e identificação: os antropólogos e a definição de terras indiggenas no Brasil, 1977-2002. Rio de Janeiro: Contra Capa/Laced/CNPq/Faperj/IIEB.

BRASIL. Decreto $n^{\circ} 4.887$, de 20 de novembro de 2003. Regulamenta o procedimento para identificação, reconhecimento, delimitação, demarcação e titulação das terras ocupadas por remanescentes das comunidades dos quilombos de que trata o art. 68 do Ato das Disposições Constitucionais Transitórias. Brasília, 2003c. Disponível em: <http://www.planalto.gov.br/ ccivil_03/decreto/2003/d4887.htm>. Acesso em 30 de outubro de 2018.

BRASIL. Ministério do Desenvolvimento Agrário. Instituto Nacional de Colonização e Reforma Agrária. Instrução normativa no 16, de 24 de março de 2004. Regulamenta o procedimento para identificação, reconhecimento, delimitação, demarcação e titulação das terras ocupadas por remanescentes das comunidades dos quilombos de que trata o art. 68 do Ato das Disposições Constitucionais Transitórias. Brasília, 2004. Disponível em: <http://www.incra.gov.br/sites/ default/files/uploads/institucionall/legislacao--/atosinternos/instrucoes/in16_240304.pdf >. Acesso em 30 de outubro de 2018.

BRASIL. Ministério do Desenvolvimento Agrário. Instituto Nacional de Colonização e Reforma Agrária. Instrução normativa $n^{\circ} 20$, de 19 de setembro de 2005. Regulamenta o procedimento para 
identificação, reconhecimento, delimitação, demarcação, desintrusão, titulação e registro das terras ocupadas por remanescentes das comunidades dos quilombos de que tratam o Art.68 do Ato das Disposições Constitucionais Transitórias da Constituição Federal de 1988 e o Decreto n 4.887 , de 20 de novembro de 2003. Brasília, 2005. Disponível em <http://www.incra.gov.br/sites/default/ files/uploads/institucionall/legislacao--/atos internos/instrucoes/in20_190905.pdf >. Acesso em 30 de outubro de 2018.

BRASIL. Ministério do Desenvolvimento Agrário. Instituto Nacional de Colonização e Reforma Agrária. Instrução normativa no 49, de 29 de setembro de 2008. Regulamenta o procedimento para identificação, reconhecimento, delimitação, demarcação, desintrusão, titulação e registro das terras ocupadas por remanescentes das comunidades dos quilombos de que tratam o Art.68 do Ato das Disposições Constitucionais Transitórias da Constituição Federal de 1988 e o Decreto n 4.887, de 20 de novembro de 2003. Brasília, 2008. Disponível em: <http://www.incra.gov.br/sites/default/ files/uploads/institucionall/legislacao--/atos-internos/instrucoes/in49_290908.pdf $>$. Acesso em 30 de outubro de 2018.

BRASIL. Ministério do Desenvolvimento Agrário. Instituto Nacional de Colonização e Reforma Agrária. Instrução normativa n ${ }^{\circ}$ 56, de 7 de outubro de 2009. Regulamenta o procedimento para identificação, reconhecimento,delimitação, demarcação, desintrusão, titulação e registro das terras ocupadas por remanescentes das comunidades dos quilombos de que tratam o Art.68 do Ato das Disposições Constitucionais Transitórias da Constituição Federal de 1988 e o Decreto n 4.887, de 20 de novembro de 2003. Brasília, 2009a. Disponível em: <http://www.incra.gov.br/sites/default/ files/uploads/institucionall/legislacao--/atos internos/instrucoes/in_56_2009_quilombolas. pdf $\rangle$. Acesso em 30 de outubro de 2018.

BRASIL. Ministério do Desenvolvimento Agrário. Instituto Nacional de Colonização e Reforma Agrária. Instrução normativa no 57, de 20 de outubro de 2009. Regulamenta o procedimento para identificação, reconhecimento, delimitação, demarcação, desintrusão, titulação e registro das terras ocupadas por remanescentes das comunidades dos quilombos de que tratam o Art. 68 do Ato das Disposições Constitucionais Transitórias da Constituição Federal de 1988 e o Decreto n 4.887, de 20 de novembro de 2003. Brasília, 2009b. Disponível em: <http://www.incra.gov.br/sites/default/ files/uploads/institucionall/legislacao--/atos-internos/instrucoes/in_57_2009_quilombolas. pdf $>$. Acesso em 30 de outubro de 2018.

CASTILHO, et al. 2014. Introdução. In: S. R. Rodrigues Castilho, A. C. de Souza Lima; \& C. Costa Teixeira (org.). Antropologia das Práticas de Poder: reflexóes etnográficas entre burocratas, elites e corporaçôes. Rio de Janeiro: Contracapa.

FERREIRA, Rebeca Campos. 2012. "Laudos Antropológicos, responsabilidades sociais. Dilemas do reconhecimento de comunidades remanescentes de quilombos". Porto Alegre, Civitas 12(2): 340358.

L'ESTOILE, Benoît de; NEIBURG, Federico; SIGAUD, Lygia (org.). 2002. Antropologia, impérios e estados nacionais. Rio de Janeiro: Relume Dumará; Fundação Carlos Chagas Filho de Amparo à Pesquisa do Estado do Rio de Janeiro (FAPERJ).

LARAIA, R. B. Apresentação. 1994. In: O. S. Silva et al. (org.). A perícia antropológica em processos judiciais. Florianópolis: Edufsc.

LIMA, Antonio Carlos de Souza. 2015. "A Antropologia e o Estado no Brasil: breves notas acerca de uma relação complexa." In: Franch et al. (Orgs). Antropologia em novos campos de atuação: debates e tensões. João Pessoa: Mídia Gráfica Editora. 
LIMA, Antonio Carlos de Souza. 2005. “Os relatórios antropológicos de identificação de terras indígenas da Fundação Nacional do Índio: notas para o estudo da relação entre a antropologia e indigenismo no Brasil, 1968-1985”. In: A. C. de Souza Lima \& H. T. Barreto Filho (Orgs.). Antropologia e Identificação. Os antropólogos e a definição de terras indígenas no Brasil, 1977-2002. Rio de Janeiro: Contra Capa Livraria. LACED/CNPq/FAPERJ/IIEB.

O’DWYER, Eliane Cantarino. 2005. “Laudos Antropológicos: pesquisa aplicada ou exercício profissional da disciplina?” In: I. Boaventura Leite (org.). Laudos periciais antropológicos em debate. Florianópolis: Nuer/ ABA.

2010. O papel social do antropólogo. A aplicação do fazer antropológico e do conhecimento disciplinar nos debates públicos do Brasil contemporâneo. Rio de Janeiro: E-papers.

SANTOS. Flavio Luis Assiz dos. 2019. Antropologia e Estado: Uma Etnografia dos Processos de Reconbecimento Territorial Quilombola na Babia (2003-2018). Tese de Doutorado em Antropologia. Salvador, UFBA.

SILVA, Alexandra Barbosa da. 2015. "Antropologia e laudos: de ética, de imparcialidade e a etnografia como processo prático". In: J. Pacheco de Oliveira, F. Mura \& A. Barbosa Silva. Laudos antropológicos em perspectiva. Brasília: ABA.

SILVA, Aracy Lopes da. 1994. "Ha Antropologia nos laudos antropológicos?” In: O. S. Silva et al. (org.). A pericia antropológica em processos judiciais. Florianópolis: Edufsc.

STEUERNAGEL, Maicon Silva. 2010. Entre Margens e Morros. A geografia narrativa dos filhos da Pedra Branca. Dissertação de Mestrado em Antropologia. Universidade Federal do Paraná, Curitiba. 


\section{FAZER LAUDOS: ALGUMAS QUESTÕES TEÓRICO-METODOLÓGICAS DE UMA $P R A ́ X I S$ ESPECIALIZADA}

Resumo: Fazer laudos se constitui numa prática profissional antropológica que afeta sobremaneira a carreira e a vida dos/das antropólogos/as, tanto por exigir-lhes competências específicas, quanto por se constituir em experiências sui generis. Neste artigo apresento algumas questões teórico-metodológicas que povoam o universo dessa prática profissional especializada, a partir do exame detalhado de laudos antropológicos, associado a entrevistas com os/as seus/suas autores/as, produzidos no bojo de processos administrativos de reconhecimento territorial quilombola em tramitação no Instituto Nacional de Colonização e Reforma Agrária (INCRA) na Bahia, de 2003 a 2018.

Palavras-chave: laudos antropológicos, antropólogos/as, práxis profissional.

\section{MAKING REPORTS: SOME THEORETICAL AND METHODOLOGICAL ISSUES OF A SPECIALIZED PRAXIS}

Abstract: Making reports is an anthropological professional practice that greatly affects the career and life of anthropologists, both by requiring them specific skills and by being sui generis experiences. In this article I present some theoretical and methodological questions that populate the universe of this specialized professional practice, from the detailed examination of anthropological reports, associated with interviews with their authors, produced in the midst of administrative processes of quilombola territorial recognition. in process at the National Institute of Colonization and Agrarian Reform (INCRA) in Bahia, from 2003 to 2018.

Keywords: anthropological reports, anthropologists, professional praxis.

RECEBIDO: 23/12/2019

APROVADO: $14 / 02 / 2020$ 